\title{
Correction to: Essential role of B metal species in perovskite type catalyst structure and activity on toluene oxidation
}

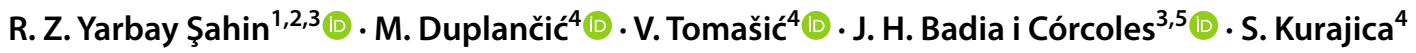

Published online: 16 February 2021

C Islamic Azad University (IAU) 2021

\author{
Correction to: \\ International Journal of Environmental Science and \\ Technology \\ https://doi.org/10.1007/s13762-021-03148-x
}

There was an error in the affiliations of the co-authors M.

Duplančić, V. Tomašić, J. H. Badia i Córcoles, S. Kurajica.

Their correct affiliations are given in this correction.

Original article corrected.

The original article can be found online at https://doi.org/10.1007/ s13762-021-03148-x.

R. Z. Yarbay Şahin

Zerrin.yarbay@bilecik.edu.tr

1 Faculty of Engineering Chemical Engineering Department, Bilecik Seyh Edebali University, Bilecik, Turkey

2 Energy Technologies Application and Research Centre Bilecik, Bilecik Şeyh Edebali University, Bilecik, Turkey

3 Department of Advanced Materials for Energy, Catalonia Institute for Energy Research (IREC), Barcelona, Spain

4 Faculty of Chemical Engineering and Technology, University of Zagreb, Zagreb, Croatia

5 Departament d'Enginyeria Química i Química Analítica, Universitat de Barcelona, Barcelona, Spain 